\title{
Immediate Effect of Postural Control of the Contra-Lateral Side on Exercise-Induced Fatigue of the Ipsi-Lateral Plantar Flexor Muscle
}

\author{
Sung Min Son \\ Department of Physical Therapy, College of Health Science, Cheongju University, Cheongju, Korea
}

\begin{abstract}
Purpose: The purpose of the current study was to examine the effects of exercise-induced fatigue of the plantar flexor muscle in the dominant ankle on the plantar flexor strength and postural control function of the contra-lateral side.

Methods: Twenty-one young adults (male: 10, female: 11) volunteered to participate in this study. An exercise-induced fatigue protocol to induce fatigue was performed in the plantar flexor of the dominant ankle. For the fatigue protocol, the participants were instructed to raise their heels as high as possible in the position with one leg stance of the dominant lower limb, and the heel was then downed after holding for 1 second. The muscle strength of the contra-lateral plantar flexor was measured using a digital muscle strength test device, and the static and dynamic postural control were tested by acquiring the center of gravity velocity while performing one leg standing. A paired t-test was used to identify the differences between the pre- and post, and the data were analyzed using SPSS 12.0 software.

Results: Comparison of the pre- and post-test data revealed a significant difference in the plantar flexor strength and dynamic postural control after exercise-induced muscle fatigue in the dominant side. On the other hand, there was no significant difference in the static postural control.
\end{abstract}

Conclusion: These findings have practical implications, suggesting that unilateral muscle fatigue affects the ankle muscle strength and postural ability of the contralateral side.

Keywords: Cross-education, Cross-effect, Fatigue, Postural control

\section{서 론}

교차교육(cross education)은 어느 편측 상지 혹은 하지가 훈련을 통해 수행에 발전이 이루어지면, 이와 교차하는 반대편 동일한 근육 수행 이 향상된다는 개념이다.1-3 이러한 교차교육의 효과는 특정 근육에 서만 국한적으로 나타나는 현상이 아니며, 또한 나이와 성별과도 연 관되어 있지 않다. ${ }^{4}$ 교차교육 효과에 대한 정확한 기전에 대해서는 아 직 명확하게 밝혀지지 않았지만, 편측에 주어진 자극이 중추신경계 의 사용 의존성 가소성(use-dependent plasticity)에 의해 뇌의 시냅스 를 재구성하여 나타난 결과로 보고 있다.5,6

편측 상지 혹은 하지에 근력강화훈련이나 과제 훈련을 실시한 후 반대측 동일한 사지의 교차교육효과를 알아보기 위해 많은 선행 연 구들이 이루어졌다.-9 Munn 등은 편측 근력 훈련이 반대측 동일한

Received Mar 19, 2018 Revised Apr 23, 2018

Accepted Apr 27, 2018

Corresponding author Sung Min Son

E-mailssm0417@hanmail.net
근육의 근력에 미치는 영향을 알아보기 위해 메타분석(meta-analysis)을 실시하였으며, 이 연구에서 교차훈련이 효과가 있음을 확인하 였다. 또한 이러한 교차교육 효과는 장시간 훈련 뿐만 아니라 단시간 훈련에서도 나타난다고 하였다. 선행 연구에서 2주 동안 비우세측 팔 꿉 관절의 굽힘 훈련이 우세측 팔꿉 관절의 굽힘 근력을 향상시켰다 고 보고하였다. ${ }^{10}$ 더욱이, 우세측 하지에 대한 4 주간의 근력강화 훈련 이 비우세측 다리를 이용한 한 발 서기 능력을 향상시켰다고 보고하 였고, ${ }^{11} \mathrm{Kim}$ 등ㄹㅇㅢ 연구에서도 엉덩관절 근력훈련을 실시한 후 반대 측 하지의 한 발 서기 능력이 향상되었다고 보고하였다. 이러한 선행 연구들의 결과는 교차교육 효과로 발생한 반대측 근력 향상과 자세 조절과 같은 수행 능력에도 영향을 줄 수 있음을 시사한다.

하지만, 지금까지 교차교육 효과에 대한 대부분의 연구들은 장시 간 반복적인 훈련프로그램을 실시하여 반대측 동일 근육에 대한 근
Copylight ( 2018 The Korea Society of Physical Therapy

This is an Open Access article distribute under the terms of the Creative Commons Attribution Non-commercial License (Http:// creativecommons.org/license/by-nc/4.0.) which permits unrestricted non-commercial use, distribution, and reproduction in any medium, provided the original work is properly cited. 
력과 수행의 향상을 평가한 연구들이 대부분이었으며, 운동프로그램 적용 후 발생하는 즉각적인 교차교육 효과에 대한 연구는 미흡하다.

Panzer 등 ${ }^{13}$ 의 연구에서는 최대 수의적 수축(maximal voluntary contraction)으로 팔꿉 관절에 굽힘과 폄을 실시할 때, 반대측 위팔두 갈래근(biceps brachii)과 위팔세갈래근(triceps brachii)에서 안정 시에 비해 근활성도가 유의한 증가가 나타났다. 이 연구 결과는 편측 근육 이 수축할 때 반대측 동일한 근육도 함께 동원됨을 의미한다. 이 연구 결과를 토대로 또 다른 관점에서 생각하면, 반복적인 운동으로 근육 의 피로가 발생할 경우 반대측 동일한 근육에도 교차 교육 효과에 대 한 영향이 있을 수 있을 것이라 생각한다. 근 피로는 운동으로 인해 단시간 근육의 힘 생성 능력이 저하되어 수의적으로 근육이 수축할 수 있는 최대 힘을 감소시킨다. ${ }^{14,15}$ 이러한 근 피로는 외부 환경에 대응 하는 반응시간, 고유수용성감각과 신경근 제어 능력에 부정적인 영 향을 준다. ${ }^{16,17}$

그래서, 본 연구의 목적은 우세측 발바닥 굽힘근에 근 피로 유발 운동 프로그램을 실시한 후 반대측 하지의 근력변화를 확인하는 것 이다. 또한 교차교육으로 발생한 근력의 변화가 자세 조절에도 영향 을 주었는지 확인하는 것이다.

\section{연구방법}

\section{1. 연구대상}

본 연구는 20 대 대학생 남자 10 명, 여자 11 명을 대상으로 하였다. 연구 자는 실험 전 모든 대상자들에게 본 실험에 대한 설명을 충분히 하였 고, 모든 대상자들은 연구자의 설명 내용을 듣고 목적을 이해하였다. 실험 전 설명을 듣고 자발적 참여에 동의한 대상자들로 실험을 실시 하였다. 대상자의 선정 기준은 1) 하지에 근 골격계 혹은 신경학적 결 함이 없는 자, 2) 실험 결과에 영향을 줄 수 있는 체계적인 운동프로 그램에 참여하지 않은 자, 3) 균형 조절에 문제가 없는 자로 하였다.

\section{2. 연구절차 및 측정도구}

모든 대상자들에게 균형 및 근력을 측정하기 전에 근 피로와 운동의 영향을 최소화하기 위해 평가 1 주일 전부터 격한 운동 및 체계적인 운동을 하지 않도록 지시하였다. 연구 대상자들의 비우세측 하지의 자세조절능력 및 근력은 우세측 발바닥 굽힘근의 근 피로 유발 운동 프로그램 적용 전과 프로그램 적용 종류 후 바로 측정하였다. 자세조 절 능력 및 근력의 측정은 연구 대상자들의 기기사용에 대한 이해도 를 충분히 이해할 수 있도록 충분한 연습 후에 실시하였다. 측정에 대 한 오차를 줄이기 위해 3 회 측정하였고, 평균값을 사용하였다.

\section{1) 우세측 발바닥굽힘근의 근 피로 유발 운동}

본 연구에서는 하지의 근 피로 유발 운동 프로그램은 Gefen 등18의 선 행연구에서 적용한 피로검사를 사용하였다. 대상자들은 우세측 다리 로 한 발 서기 자세를 취한 후 발바닥 굽힘하여 최대한 발뒤꿈치를 높 이 올리도록 지시하였으며, 1초 동안 유지한 후 다시 발뒤꿈치를 내리 는 동작을 수행하였다. 이때 무릎 관절은 최대한 편 상태를 유지하도 록 하였고, 신체 균형을 유지할 수 있도록 주변 구조물에 가벼운 접촉 을 유지할 수 있도록 허용하였다. 근 피로 유발 운동 프로그램은 1 분 동 안의 운동과 2 분간의 휴식을 1 세트로 설정하였고, 총 5 세트로 구성하 였다. 발바닥 굽힘근의 근 피로는 대상자가 운동을 더 이상 진행하지 못하겠다고 표현할 때, 운동 수행을 주어진 빈도로 수행하지 못할 때, 5 세트의 운동을 완료했을 때를 근 피로가 발생한 것으로 인식하였다. ${ }^{19}$

\section{2) 한 발 서기 자세 조절 능력 측정}

비우세측 다리로 한 발 서기 자세 조절 능력을 평가하기 위해 힘판 기 반의 자세균형 시스템(IBalance, Cybermedic Co., Korea)을 사용하였 다. 이 장비는 4 개의 로드셀(load cell)이 장착된 $600 \times 400$ 크기의 힘판 을 이용하여 신체동요에 대한 압력중심(center of press)의 변화를 측 정할 수 있도록 설계되었으며, 자세 안정성을 유지하는 동안 동요속 도와 이동거리를 측정하여 자세조절 능력을 평가할 수 있다. 본 연구 에서 자세조절을 평가하기 위해 단단한 힘판 위에서 측정하는 방법 과 동적 자세조절 능력을 평가하기 위해 힘판 위에 스펀지를 위치시 켜 불안정성을 높여 평가하는 두 가지 방법을 측정하였다. 측정 시 자 세는 비우세측 다리를 미리 표시한 지점 위에 엄지발가락을 위치시 켰고, 양손은 가슴 위에 교차하도록 하였다. 모든 대상자들은 단단한 면 위에서 연습을 실시하였고, 두 가지 방법의 측정 순서는 무작위순 서로 하였다.

\section{3) 비우세측 발바닥 굽힘근 근력 측정}

본 연구에서 대상자들의 발바닥 굽힘근의 근력을 측정하기 위해서 디지털 근력 측정계를 사용하였다(Commander Digital Evaluation Products, JTech medical,. USA). 근력 측정은 대상자를 엎드려 누운 자 세에서 무릎 관절은 최대한 폄 할 수 있도록 하였고, 근력측정기의 도 자를 발바닥에 위치시켰다. 대상자들에게 연구자가 구두로 “시작”이 란 신호를 할 때 발목을 최대한 발바닥 굽힘하여 도자를 밀도록 지시 하였다. 총 3 회 측정하였고, 측정간 1 분의 휴식을 주었다.

\section{3. 자료처리}

모든 측정값들에 대한 자료분석은 SPSS 12.0 버전을 사용하였다. 대 상자들의 연령, 키, 몸무게는 기술통계를 통해 확인하였다. 우세측 발 바닥 굽힘근의 근 피도도 유발 운동 프로그램이 비우세측 발바닥 굽 
Table 1. The general characteristics of subjects

\begin{tabular}{lc}
\hline & Subject $(\mathrm{n}=21)$ \\
\hline Male/Female & $10 / 11$ \\
Age (year) & $21.81 \pm 1.60$ \\
Height $(\mathrm{cm})$ & $167.70 \pm 9.84$ \\
Weight $(\mathrm{kg})$ & $60.86 \pm 9.29$ \\
\hline
\end{tabular}

Values are presented as mean \pm standard deviation.

힘근의 근력과 한발서기 자세 조절 기능의 전-후 변화를 비교하기 위 해 대응표본 t-검정(paired t-test)을 실시하였다. 유의 수준은 0.05 로 설 정하였다.

\section{결 과}

대상자들의 일반적 특성은 Table 1과 같다. 우세측 발바닥 굽힘근의 근 피로 운동 프로토콜 적용 전과 후에 비우세측 발바닥 굽힘근의 근 력과 정적. 동적 자세조절 변화는 table 2 와 같이 나타났다. 근 피로 운 동 프로토콜 적용 전·후 비교에서 비우세측의 발바닥 굽힘근의 근력 은 근 피로 운동 프로토콜 전과 비교하였을 때 유의한 감소가 나타났 으며, 동적 자세조절에서도 근 피로 운동 프로토콜 적용 후에 유의하 게 압력중심의 이동거리가 증가하였다 $(\mathrm{p}<0.05)$. 하지만, 정적 자세조 절에서는 근 피로 운동 프로토콜 적용 전. 후에서 유의한 차이를 보 이지 않았다 $(\mathrm{p}>0.05)$.

\section{고 찰}

교차교육 효과에 대한 선행연구들은 대부분 장시간 훈련 프로그램 을 실시하여 반대측 동일 근육에 대한 근력과 수행을 평가한 연구들 이 대부분이었으며, 운동 프로그램 적용 후에 즉각적인 교차교육 효 과에 대한 연구는 미흡하였다. 본 연구에서는 우세측 발바닥굽 힘근 에 근 피로 유발 운동 프로그램이 교차교육 효과로서 반대측 하지의 근력변화와 자세 조절에 영향을 미치는지 확인하였다. 본 연구의 결 과는 편측 발바닥 굽힘근에 발생한 피로는 반대측 발바닥 굽힘근의 근력을 감소시켰고, 동적 자세조절 능력에도 부정적인 영향을 발생 시켰다.

본 연구 결과 편측 근 피로 유발 운동 프로그램 종료 후 반대측 발 바닥 굽힘근의 근력이 감소된 것을 확인하였다. 선행연구에서 교차교 육 효과는 편측 사지에서 반복적으로 근육을 움직이거나 동작을 수 행할 때 반대측의 동일한 근육에 대해 근력과 동작 수행 능력에 영향 을 준다고 정의하고 있다. 이는 교차교육효과는 운동의 형태나 훈련 과제에 따라 달라질 수 있음을 시사하며, 본 연구에서는 선행연구들 과 달리 우세측 발바닥 굽힘근에 적절한 강도로 훈련을 지속적으로
Table 2. Comparison of muscle strength of contra-lateral plantar flexor according to exercise-induced fatigue of ispi-lateral side

\begin{tabular}{lccc}
\hline & Pre & Post & $\mathrm{p}$ \\
\hline Muscle strength $\left(\mathrm{kg} / \mathrm{cm}^{2}\right)$ & $53.80 \pm 7.83$ & $52.08 \pm 6.94$ & $0.029^{\star}$ \\
Postural control $(\mathrm{cm} / \mathrm{sec})$ & & & \\
SPS & $10.44 \pm 3.68$ & $10.95 \pm 3.68$ & 0.189 \\
DPS & $11.35 \pm 4.06$ & $14.20 \pm 5.02$ & $0.000^{\star}$ \\
\hline
\end{tabular}

Values are presented as mean \pm standard deviation. SPS: static postural control, DPS: dynamic postural control. ${ }^{*}$ significant difference between pre and post $(p<0.05)$.

수행한 것이 아니라 일시적인 근 피로 유발 운동 프로그램을 수행하 는 과정에서 나타난 우세측 발바닥 굽힘근 근 피로가 교차교육 효과 를 통해 비우체측 수축에 영향을 준 것으로 생각된다. Hortobagyi 등5 의 연구에서 고강도 근력 훈련은 글루타민 흥분성 신경전달물질을 증가시키고(glutaminergic excitatory neurotransmitters), 이는 동측 대 뇌운동피질에서 억제성 사이신경원(inhibitory interneurons)의 활성 도가 감소하여 대뇌반구 사이의 연계를 증가시키는 작용을 한다고 하였다. 이러한 효과는 반대측 동일 근육에도 주행하는 신경원의 활 성을 증가시켜 수의적인 운동을 계획하고 실행하는 것과 동일한 효 과를 초래한다고 할 수 있으며, 반대측 사지에 근력강화 효과뿐만 아 니라 근 피로도 영향을 줄 수 있을 것이라 생각된다.

본 연구에서 비우세측 발바닥 굽힘근의 근력 감소와 더불어 한 발 서기 자세를 이용한 자세조절 능력을 평가하였다. 본 연구의 결과에 서 동적 자세조절에서 동요속도가 유의하게 증가한 결과가 나타났 다. 자세동요의 증가는 일정한 자세를 유지한 상태에서 자세동요가 더 커졌다는 것을 의미하고 있다. Park 등 20 의 연구에서 뇌졸중 환자 들의 비마비측 무릎 혹은 발목 관절의 근 피로 유발은 자세 조절 능 력과 보행 능력에 부정적인 영향을 발생시킨다고 하였고, Springer와 Pincivero $^{21}$ 연구에서 편측 하지의 근 피로 유발 후 한 발 서기 자세 조 절 능력이 감소하였다고 보고하였다. 이와 같이 많은 선행연구들에서 근력과 자세조절 사이에 긴밀한 상관성이 있음을 제시하였다. ${ }^{20,22-24}$

하지만, 정적 자세조절에서는 근 피로 운동 유발 프로그램 전. 후 자세동요가 증가를 보였지만, 유의한 차이가 보이지 않았다. 이는 대 상자가 젊은 성인으로만 구성되어 있으며, 불안정한 면에서 실시한 동적 자세조절 평가와 달리 정적 자세조절 평가는 단단한 면에서 수 행하여 유의한 결과 차이가 나타나지 않은 것으로 생각된다.

근 피로는 고강도 운동을 반복적이거나 장시간 동안 수행할 때 근 육의 수축 능력이 일시적으로 감소되는 현상을 말한다..$^{5}$ 이때 발생 한 피로는 근수축의 반응시간과 근력을 감소시킬 뿐만 아니라 관절 의 운동감각과 위치 감각에 대한 정보를 수용하고 처리하는 고유수 용성감각에도 영향을 미친다고 하였다. ${ }^{23,25,26}$ 본 연구 결과는 근 피로 유발 운동 프로그램 적용의 즉각적인 교차교육 효과로서 우세측 발 
바닥 굽힘근의 근 피로는 비우세측 하지에 근력의 감소와 균형 능력 을 감소시킬 수 있음을 확인하였다. 이는 교차교육은 편측의 근력이 나 수행능력의 훈련이 반대측 동일 근육의 기능에 긍정적인 효과를 가져올 수도 있지만, 편측의 근 피로를 유발시키는 프로그램은 반대 측 동일 근육에 짧은 시간일지라도 부정적인 영향을 줄 수 있음 시사 한다. 많은 선행연구들에서는 장시간 규칙적인 훈련프로그램을 적용 하여 반대측 동일 근육에 대한 근력과 수행의 향상을 평가한 연구들 이었다.7-10,12 하지만, 본 연구에서는 우세측 발바닥 굽힘근에 대한 근 피로 유발 운동 프로그램을 적용 후 즉각적인 교차교육 효과를 확인 하였고, 본 연구 결과는 임상적으로 중요한 의미를 확인한 연구라 사 료된다.

본 연구의 결과를 해석하기에 고려해야 할 몇 가지 제한점이 있다. 우선 본 연구는 실험군과 비교할 대조군을 설정하지 못하였다. 그래 서 본 연구의 결과가 시간에 따른 효과인지 운동을 통한 효과인지를 확인할 수 없었다. 둘째 대상자들의 수가 적고 20대 젊은 대학생을 대 상으로 연구가 진행되었기 때문에 다른 연령대에 대해서 일반화하기 에 어려움이 있다. 셋째, 우세측 근 피로도 측정 시 표면 근전도와 같 은 과학적 방법으로 확인하지 못했다는 것이다. 향후 연구에서는 이 러한 제한점을 보완하여 연구들이 지속적으로 이루어져야 할 것이 라 생각된다.

\section{참고문헌}

1. Zhou S. Chronic neural adaptations to unilateral exercise: mechanisms of cross education. Exerc Sport Sci Rev. 2000;28(4):177-84.

2. Munn J, Herbert RD, Gandevia SC. Contralateral effects of unilateral resistance training: a meta-analysis. J Appl Physiol. 2004;96(5):1861-6.

3. Goodwill AM, Daly RM, Kidgell DJ. The effects of anodal-tdcs on crosslimb transfer in older adults. Clin Neurophysiol. 2015;126(11):2189-97.

4. Lee M, Carroll TJ. Cross education: possible mechanisms for the contralateral effects of unilateral resistance training. Sports Med. 2007;37(1):114.

5. Hortobagyi T, Taylor JL, Petersen NT et al. Changes in segmental and motor cortical output with contralateral muscle contractions and altered sensory inputs in humans. J Neurophysiol. 2003;90(4):2451-9.

6. Carroll TJ, Riek S, Carson RG. The sites of neural adaptation induced by resistance training in humans. J Physiol. 2002;544(Pt 2):641-52.

7. Shima N, Ishida K, Katayama K et al. Cross education of muscular strength during unilateral resistance training and detraining. Eur J Appl Physiol. 2002;86(4):287-94.

8. Bezerra P, Zhou S, Crowley Z et al. Effects of unilateral electromyostimulation superimposed on voluntary training on strength and cross-sectional area. Muscle Nerve. 2009;40(3):430-7.

9. Farthing JP, Borowsky R, Chilibeck PD et al. Neuro-physiological adap- tations associated with cross-education of strength. Brain Topogr. 2007; 20(2):77-88

10. Bemben MG, Murphy RE. Age related neural adaptation following short term resistance training in women. J Sports Med Phys Fitness. 2001;41(3):291-9.

11. Schlenstedt C, Arnold M, Mancini M et al. The effect of unilateral balance training on postural control of the contralateral limb. J Sports Sci. 2017;35(22):2265-71

12. Kim K, Cha YJ, Fell DW. The effect of contralateral training: influence of unilateral isokinetic exercise on one-legged standing balance of the contralateral lower extremity in adults. Gait Posture. 2011;34(1):103-6.

13. Panzer S, Schinowski D, Kohle D. Cross-education and contralateral irradiation. J Hum Kinet. 2011;27:66-79.

14. Mutch BJ, Banister EW. Ammonia metabolism in exercise and fatigue: a review. Med Sci Sports Exerc. 1983;15(1):41-50.

15. Allen DG, Westerblad H. Role of phosphate and calcium stores in muscle fatigue. J Physiol. 2001;536(Pt 3):657-65.

16. Caron O. Effects of local fatigue of the lower limbs on postural control and postural stability in standing posture. Neurosci Lett. 2003;340(2):836.

17. Vuillerme N, Burdet C, Isableu B et al. The magnitude of the effect of calf muscles fatigue on postural control during bipedal quiet standing with vision depends on the eye-visual target distance. Gait Posture. 2006; 24(2):169-72

18. Gefen A, Megido-Ravid M, Itzchak Y et al. Analysis of muscular fatigue and foot stability during high-heeled gait. Gait Posture. 2002;15(1):5663 .

19. Barbieri FA, dos Santos PC, Vitorio R et al. Effect of muscle fatigue and physical activity level in motor control of the gait of young adults. Gait Posture. 2013;38(4):702-7.

20. Park SW, Son SM, Lee NK. Exercise-induced muscle fatigue in the unaffected knee joint and its influence on postural control and lower limb kinematics in stroke patients. Neural Regen Res. 2017;12(5):765-9.

21. Springer BK, Pincivero DM. The effects of localized muscle and wholebody fatigue on single-leg balance between healthy men and women. Gait Posture. 2009;30(1):50-4.

22. Son SM. Changes of one-leg standing balance of ipsilateral and contralateral lower-limb following unilateral isokinetic exercise of ankle joint in young adults. J Kor Phys Ther. 2015;27(6):430-3.

23. Gribble PA, Hertel J. Effect of lower-extremity muscle fatigue on postural control. Arch Phys Med Rehabil. 2004;85(4):589-92.

24. Harkins KM, Mattacola CG, Uhl TL et al. Effects of 2 ankle fatigue models on the duration of postural stability dysfunction. J Athl Train. 2005; 40(3):191-4.

25. Gribble PA, Hertel J, Denegar CR et al. The effects of fatigue and chronic ankle instability on dynamic postural control. J Athl Train. 2004;39(4):3219.

26. Salavati M, Moghadam M, Ebrahimi I et al. Changes in postural stability with fatigue of lower extremity frontal and sagittal plane movers. Gait Posture. 2007;26(2):214-8. 